$$
\text { DOE/NV/10812-T8 }
$$

DOE/NV/10872--T8

DOE PROJECT YEARLY REPORT

Task A.2.a-Reviow of Container Design Concepts

DE92 014666

Dr. Samir Moujaes and Yao Lei

This report is a compilation of our work for the school year of 1990-91 concerning the thermal effects of the heat generation from the nuclear waste on the container material and surrounding rock.

At this time we are still in the process of reviewing some of the pertinent literature relevant to the thermal design of the container. The survey has included some of the LLNL reports as well as those in the open literature. Here is a listing of the reports and papers which we have compiled:

LLNL reports:

"THERMAL MODELING OF NUCLEAR WASTE PACKAGE DESIGNS FOR DISPOSAL IN TUFF", J.N.Hockman and W.C.O'Neal, Proceedings of the ANS/ASME Waste Management 84 Meeting, Tucson, AZ(March 11-15, 1984), Vol.1,pp. $441-488$

"THERMAL ANALYSIS OF NNWSI CCN"ETTTAL WASTE PACKAGE DESIGNS", W.Stein, J.Hockman, and W.O'Neal, Report UCID-20091, April,1984

Abstract--Iawrence Livermore National Laboratory is involved in the design and testing of high level nuclear waste packages. Many of the aspects of waste package design and testing (e.g.. corrosion and leaching) depend in part on the temperature history of the emplaced packages. This report discusses thermal modeling and analysis of various emplaced waste package conceptual designs including the models used, the assumptions and approximations made, and the results obtained.

"THE 'PLUS' FAMILY A SET OF COMPUTER PROGRAMS TO EVALUATE ANALYTICAL SOLUTIONS OF THE DIFFUSION EQUATION", D.N. MONTan, Report UCID-20680, February, 1986, February 1987

Abstract--These two reports are intended to describe, document and provide instructions for the use of a set of computer 
DISCLAIMER

This report was prepared as an account of work sponsored by an agency of the United States Government. Neither the United States Government nor any agency thereof, nor any of their employees, makes any warranty, express or implied, or assumes any legal liability or responsibility for the accuracy, completeness, or usefulness of any information, apparatus, product, or process disclosed, or represents that its use would not infringe privately owned rights. Reforence herein to any specific commercial product, process, or service by trade name, trademark, manufacturer, or otherwise does not necessarily constitute or imply its endorsement, recommendation, or favoring by the United States Government or any agency thereof. The views and opinions of authors expressed herein do not necessarily state or reflect those of the United States Government or any agency thereof. 
programs commonly referred to as the PLUS family. These programs were designed to numerically evaluate simple analytic solutions of the diffusion equation. The second report is the additions of the first one.

"THERMOMECHANICAL SCOPING CALCULATIONS FOR THE WASTE PACKAGE ENVIRONMENT TESTS", T.R.Butkovich and J.L.YOW, Report UCID-20758, March 1986

Abstract--During the site characterization phase of the Nevada Nuclear Waste Storage Investigation Project, Tests are planned to provide field information on the hydrological and thermomechenical environment. These results are needed for assessing performance of stored waste packaqes emplaced at depth in excavations in a rock mass. Scoping calculations were performed to provide information on displacements and stress levels attained around excavations in the rock mass from imposing a thermal load designed to simulate the heat produced by radioactive decay. In this way, approximate levels of stresses and displacements are available for choosing instrumentation type and sensitivity as well as providing indications for optimizing instrument emplacement during the test.

"THERMAL CALCULATIONS PERTAINING TO EXPERIMENTS IN THE YUCCA MOUNTAIN EXPLORATORY SHAFT", D.N. Montan, Report UCID_20780, March 1986

abstract-Waste Package Environment Test are being planned for the NNWSI Exploratory Shaft to provide information about the near field hydrological, thermal, and mechanical environment of the waste package for use in assessing the expected performance of the waste package subsystem. The rationale of the tests is driyen by the need for this information, but is constrained by the measurement capabilities that can be applied in situ, and by the ability of analytical and numerical models to use the data obtained with the measurements. A secondary purpose of the tests is to provide che option of testing certain components that may be part of the engineered barrier system.

"THERMAL AND MECBANICAL CODES FIRST BENCHMARK EXERCISE PART I: THERMAL ANALYSIS (Yucca Mountain Project)" Laurence S. Costin, Stephen J. Bauer SAND88-1221.UC-814, June 1990

Abstract--Thermal and mechanical models for intact and jointed rock mass behavior are being developed, verified, and validated at Sandia National Laboratories for the Yucca Mountain Project. Benchmarking is an essential part of this effort and is the primary tool used to demonstrated verification of engineering software used to solve thermalmechanical problems. This report presents the results of the first phase of the first 
thermalmechanical benchmark exercise. In the first phase of this exercise, three finite element codes for nonlinear heat conduction and one coupled thermoelastic boundary element code were used to solve the thermal portion of the benchmark problem. The codes used by the participants in this study were DOT, COYOTE, SPECTROM-41, and HEFF. The problem solved by each code was a two-dimensional idealization of a series of drifts whose dimensions approximate those of the underground layout in the conceptual design of a prospective repository for high-level radioactive waste at Yucca Mountain. The initial results submitted by the participants showed that the finite element solutions agreed to within 18 , with the exception of one of the three solutions produced by COYOTE. This solution differed slightly from the others because of the different time-step size used in the pre-emplacement time regime of the problem. A revised solution was submitted that was nearly identical to the other solutions. The boundary element code HEFF was also used in this exercise because it calculates a solution to the thermal problem using an approximate analytical method and thus provides a means of comparing the finite element solutions with a solution obtained by an independent method. In addition, the comparison provides a means of determining the effect of the approximations made in $\mathrm{HEFF}$ on the thermal solution of a typical repository problem.

"NUMERICAL MODELING OF THE THERMAL AND HYDROLOGICAL ENVIRONMENT AROUND A NUCLEAR WASTE PACKAGE USING THE EQUIVALENT CONTINUUM APPROXIMATION: HORIZONTAL EMPLACEMENT", John Nitao, Report UCID21444 , May 1988

Abstract--In support of the investigations for an underground high-level nuclear waste repository at Yucca Mountain, Nevada, we have performed computer simulations of the immediate thermal and hydrological environment around a nuclear waste package. Calculations of this type will be needed for waste package design, performance assessment, and radionuclide transport analysis. Two dimensional computer simulations using a modified version of the TOUGH code were run for an idealized configuration derived from the: COVE 3 benchmarking effort consisting of a single spent fuel waste package with laterally periodic boundary conditions. The model domain extended downward to the water table and upward to the ground level. Fluid behavior in the rock was modeled using the equivalent continuum approximation. Runs wera ma with surface water influx rates at the surface set tu 0 $c$.', and $1.0 \mathrm{~mm} / \mathrm{yr}$. A significant amount of code modification ari development was needed in order to develop the capability to run these types of problems out to the long time spans required. since any significant trinsport of non-gaseous radionuclides will involve liquid water as a main vehicle of movement, and since liquid water, if present, will also contribute to waste package corrosion, its presence is of vital concern. Initial heating from the radioactive decay will vaporize 
the liquid pore water around the waste package. Of major interest to waste container design is the time at which possible wetting of the package occurs during the subsequent cool-down period. Our simulations showed that vapor transport and capillary condensation are the major mechinisms of water movement early in the cool-down period. However, the amount of liquid water in the rock next the waste package during this time is very small and will have very low mobility, although the diffusive transport properties of this water are not exactly known. In our simulations the main front of water returns to the borehole wall at approximately 1000 years from emplacement as it is drawn by capiliary imbibition. At no time during the 2600 year time span of our simulation does the water saturation of the rock next to the borehloe wall increase above initial native saturation. The values of these two time periods as well as the other predictions reported in this paper are highly preliminary due to the current uncertainly in the model input parameters and the sub-models used in our simulations. However, it is seen that the effect of hydrological fluid flow on the thermal history may be significant. Considerable work needs to be done to develop better models of fluid behavior in partially fractured rock and more experimental data is needed to accurately model the waste package environment.

"THERMAL PERFORMANCE OF A BURIED NUCLEAR WASTE STORAGE CONTAINER STORING A HYBRID MIX OF PWR AND BWR SPENT FUEL RODS", G. JOhnsOn, Report UCID-21414, Sep, 1988

Abstract--Lawrence Livermore National Laboratory will design, model, and test nuclear waste packages for use at the Nevada Nuclear Waste Storage Repository at Yucca Mountain, Nevada. One such package would store tightly packed spent fuel rods from both pressurized and boiling water reactors. The storage container provides the primary containment of the nuclear waste and the spent fuel rod cladding provides secondary containment. A series of transient conduction and radiation heat transfer -nalyses was run to determine for the first $1000 \mathrm{yr}$. of storage if the temperature of the tuff at the borehole wall ever falls below $97 \mathrm{C}$ and whether the cladding of the stored spent fuel ever exceeds $350 \mathrm{C}$. Limiting the borehole to temperatures of $97 \mathrm{C}$ or greater helps minimize corrosion by assuring that no condensed water collects on the container. The $350 \mathrm{C}$ cladding limit minimize the possibility of creep-related failure in the spent fuel rod cladding. For a series of packages stored in a $8 \times 30 \mathrm{~m}$ borehole grid where each package contains 10-yr.-old spent fuel rods generating $4.74 \mathrm{~kW}$ or more, the borehole wall stays above 97 $C$ for the full 1000-yr. analysis period. For the 4.74-kW load, the peak cladding temperature rises to just below the $350 \mathrm{C}$ limit about 4 years after emplacement. If the packages are stored using the spacing specified in the Site Characterization Plan ( $15 \mathrm{ft}$. $x$ $126 \mathrm{ft.l}$, a maximum of $4.1 \mathrm{~kW}$ per container may be stored. If the $0.05-m-t h i c k$ void between the container and the borehole wall is 
filled with loosely packed bentonite, the peak cladding temperature rises more than $40 \mathrm{C}$ above the allowed cladding limit. In all cases the dominant heat transfer mode between container components is thermal radiation.

"PROTOTYPE HEATER TEST OF THE ENVIRONMENT AROUND A SIMULATED WASTE PACKAGE", A.L. Ramirez,T.A. Buscheck, R. Carlson, W. Daily, V.R. Latorre, K. Lee, W. Lin, N. Mao, D. Towse, T.S. Ueng, and D. Watwood, Report UCRL-101693, Dec. 1989

Abstract--This paper presents selected results obtained during the 301 day duration of the Prototype Engineered Barrier system Field Test (PEBSFT) performed in G-tunnel within the Nevada Test site. The test described is a precursor to the Engineered Barrier Systems Field Tests (EBSFT) planned for the Exploratory Shaft Facility in Yucca Mountain. The EBSFT will consist of in situ tests of the geohydrologic and geochemical environment in the near field (within a few meters) of heaters emplaced in welded tuff to simulate the thermal effects of waste packages. The paper: discusses the evolution of hydrothermal behavior during the prototype test, including rock temperature, changes in rock moisture content, air permeability of fractures, and gas-phase humidity in the heater borehole.

"V-TOUGH -AN ENHANCED VERSION OF THE 'TOUGH' CODE FOR THE THERMAL AND HYDROLOGIC SIMULATION OF LARGE-SCALE PROBLEMS IN NUCLEAR WASTE ISOLATION", J.J Nitao, Report UCID-21954, Sep. 1989

Abstract--The TOUGH code developed at Lawrence Berkeley Laboratory (LBL) is being extensively used to numerically simulate the thermal and hydrologic environment around nuclear waste prckajes in the unsaturated zone for the Yucca Mountain Project. At the Lawrence Livermore National Laboratory (LLNL) we have rewritten approximately 80 percent, of the TOUGH code to increase its speed and incorporate new options. The geometry of many problems requires large numbers of computational elements in order to realistically model detailed physical phenomena, and, as a result, large amounts of computer time are needed. In order to increase the speed of the code we have incorporated fast linear equation solvers, vectorization of substantial portions of code, improved automatic time stepping, and implementation of table look-up for the steam table properties. These enhancements have increase the speed of the code for typical problems by a factor of 20 on the Cray 2 computer. In addition to increase in computational efficiency we have added several options: vapor pressure lowering; equivalent continuum treatment of fractures; energy and material volumetric, mass and flux accounting; and stefan-Boltzmann radiative heat transfer.

"THERMAL CALCULATIONS PERTAINING TO A PROPOSED YUCCA MOUNTAIN 
NUCLEAR WASTE REPOSITORY", Gary I. Johnson, Donal N. Montan, report UCRL-ID-103534, February 1990

Abstract--In support to the Yucca Mountain Project waste package and repository design efforts, ILNL conducted heat-transfer modeling of the volcanic tuff in the repository. The analyses quantify: (a) the thermal response of a finite size, uniformly loaded repository where each panel of emplacement drifts contains the same type of heat source; (b) the response given a realistic waste stream inventory to show the effect of inter-panel variations; and (c) the intra-panel response for various realistic distributions of sources within the panel. The calculations, using the PLUS family of computer codes, are based on a linear superposition, in time and space, of the analytic solution of individual, constant output point sources located in an infinite, isotropic, and homogeneous medium with constant thermal properties.

On the other hand we have proceeded to do some preliminary computation using Math Cad to simulate the physical process which involves the heat dissipated from the container to the surface of the rock in the air gap. This process involves generally heat exchange by convection as well as radiation.

Dr. Skaggs has suggested a design for the container which uses three layers of materials. The outside layer is a 1/4" of copper, the sandwiched layer is $4^{\prime \prime}$ concrete and the inner layer in contact with the waste to be a 1/4" steel layer (see Figure 1.). of course the result of these calculations should be only construed as rough calculations to shed some light on Dr. Skaggs' design in regards to any impending thermal failure due to high temperatures in the concrete layer.

In the Math Cad simulation, an assumpition of $95 \mathrm{C}$ was made at the rock borehole wall, the size of the container was $4.57 \mathrm{~m}$ tall with $0.7112 \mathrm{~m}$ in diameter, the air gap between the container and the borehole wall was $0.127 \mathrm{~m}$ ( $5 \mathrm{in.}$ ) this assumption was made under the constrain of the maximum air gap high to thickness ratio of 40 , for using the equation:

$$
N u_{L}=0.046 * R_{L}{ }^{1 / 3}
$$


to calculate the free convection heat transfer in the air gap, and was used to bound the possible values of heat input to the problem. These values are 500-5000 W the temperature values for the four surfaces of the container for the two cases were:

$$
500 \mathrm{~W} \quad 5000 \mathrm{~W}
$$

Outside Copper Surface $\quad 101.06 \mathrm{C} \quad 145.656 \mathrm{C}$

Copper-Concreted

Interface

$101.062 \mathrm{C} \quad 145.679 \mathrm{C}$

Concrete-steel

Interface

$105.336 \mathrm{C} \quad 188.418 \mathrm{C}$

Steel Interface $\quad 105.348 \mathrm{C} \quad 188.536 \mathrm{C}$

for more detail of the calculation see Addendum A.

Of course as expected the results show a significantly higher average temperature with the $5000 \mathrm{~W}$ than with the $500 \mathrm{~W}$. Work is underway now to simulate more realistically the container along with the rock bed by extending the problem solution field about 300 meters above and below where the containers are placed. Parallel to this effort a data based library search was completed to investigate any previous work performed analytically or experimentally on the problem of combined heat transfer problem between the concentric cylinders with heat generation inside the inner cylinder. It was found that no attempt has been made to model this phenomenon. The papers that were reviewed showed that most previous works related to boundary conditions that were not relevant to our case. The reviewed literature yielded a few papers that dealf with heat transfer in concentric cylinders and are:

"MIXED CONVECTION IN VERTICAL, CYLINDRICAL ANNULI", M.A. Hessami, G. DE Vahl Davis, E. Leonardi and J. A. Reizes, J HEAT TRANSFER. Vol.30.No.1.pp. 151-164. 1987, Printed in Great Britain.

Abstract--The laminar flow patterns and heat transfer for air contained in the enclosure formed between two vertical, concentric cylinders and two horizontal planes have been studied numerically. The inner cylinder and one of the horizontal planes are heated and rotated about the vertical axis, the other 
horizontal plane and outer cylinder are cooled and kept stationary. This geometry simulates the gaps at the end of the rotor of a small, air-cooled, vertically mounted electric motor. The results facilitate the thermal design of such motor.

The influences of geometry(described by the radius ratio $R$ and aspect ratio $A), R a$ and $R e$ on temperature and velocity distributions have been investigated. Solutions have been obtained for $.25<A<4.0,1.2<R<8.0,10<\operatorname{Re}<300$ and $10^{3}<\operatorname{Ra}<10^{5}$. It has been found that for low values of $R a$ and high values of $R e$ the flow is dominated by centrifugal forces, whereas for high A and Ra buoyancy effects determine the flow patterns and, therefore, the heat transfer. Monocellular flow patterns have been found for the cases where one of these forces is dominant; otherwise two- or three-cell structures have been obtained.

"NUMERICAL STUDIES OF MIX CONVECTION FLOWS IN THE ANNULUS BETWEEN VERTICAL CONCENTRIC CYLINDERS WITH ROTATING INNER CYLINDER", Kenneth S. Ball, and Bakhtier Farouk

--This paper is a numerical study of the heat transfer characteristics and flow patterns which develop around a rotating, heated, vertical cylinder enclosed within a stationary concentric cylinder. The experiment set-up is a tall annulus(aspect ratio of 10 ) with fixed, adiabatic horizontal endplates and a radius ratio of 2 has been considered.

"DEVELOPING LAMINAR FREE CONVECTION IN AN OPEN ENDED VERTICAL ANNULUS WITH A ROTATING INNER CYLINDER", M. A. I. El-Shaarawi, and A. Sarhan, TRANSACTIONS OF THE ASME JOURNAL OF HEAT TRANSFER, AUGUST 1981, VOL.103

--A finite-difference scheme is developed for solving the boundary layer equations governing the laminar free convection flow in open ended vertical concentric annuli with rotating inner wall. Numerical results are presented for fluid of $\mathrm{Pr}=0.7$ in an annulus of ratio 0.5 under the thermal boundary conditions of one wall being isothermal. and the opposite wall ad.abatic.

"VELOCITY AND TEMPERATURE DISTRIBUTIONS IN VERTICAI CONCENTRIC ANNULUS WITH COMBINED FREE AND FORCED LAMINAR CONVECTION", Tamotsu Hanzawa, Akihisa Sako and Runnio Kato, JoURNAL O CH: IICAL ENGINEERING OF JAPAN, Vol. 19 No. 21986

---Velocity and temperature distributions and heat transfer coefficient with combined free and forced laminar convection were investigated for annular flow between two vertical concentric cylinders, where a part of the inner cylinder was heated. 
"HEAT TRANSFER AND FLOW IN A SHORT, VERTICAI, INTERNALLY HEATED ANNULUS WITH A ROTATING OUTER BOUNDARY", J. S. COOmbs and S. D. Probert, JOURNAL OF MECHANICAL ENGINEERING SCIENCE, Vol.14. No.6 DEC 1972

---Experimental determinations were made of the steady-state heat fluxes and velocity profiles in water between two vertical concentric cylinders, the heated inner cylinder being stationary while the outer cylinder was rotated in ambient temperature air.

"NON-NEWTONIAN FLOW BETWEEN CONCENTRIC CYLINDERS AND THE EFFECTS OF FINITE COMPRESSIBILITY", J. C. Rainwater and H. J. M. Hanlev, INTERNATIONAL JOURNAL OF THERMALPHYSICS. VOI.6. NO.6. NOV. 1985

---A study of the problem of non-Newtonian flow between vertical, rotating concentric cylinders.

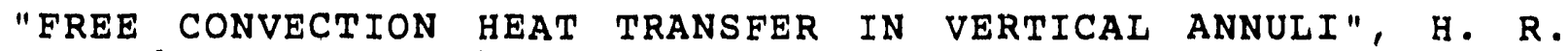
Nagendra, M. A. Tirunarayanan and A. Ramachandran, CHEMICAL ENGINEERING SCIENCE, 1970, Vol.25, pp 605-610

--Free convection heat transfer in vertical concentric, cylindrical anruli is investigated analytically and experimentally. The approximate double boundary layer model used by Emery and Chu for the case of vertical parallel plates is extended to the present case in obtain heat transfer correlations. The length ratio of the inner cylinder and Rayleigh number, were used in the derivation of correlations for the annuli. The heating rate for the inner cylinder was very small.

"COMBINED FORCED-FREE LAMINAR CONVECTION IN THE ENTRY REGION OF A VERTICAL ANNULUS WITH ROTATING INNER CYLINDER", M. A. I. ElShaarawi and A. Sarhan, INTERNATIONAL JOURNAL OF HEAT AND MASS TRANSFER, Vol.25, No.2, FEB. 1982

--Numerical results of a finite difference scheme are presented for the developing combined forced-free laminar boundary layer flow in a vertical concentric annulus with a rotating inner cylinder.

"THE EFFECT OF TEMPERATURE GRADIENT ON THE STABILITY OF FLOW BETWEEN VERTICAL, CONCENTRIC, ROTATING CYLINDERS", M. M. SOIOUI and J. E. R. Coney, JiURNAL OF MECHANICAL ENGINEERING SCIENCE, Vol.21, No.6, DEC 1979

---The effect of a radial temperature gradient on the hydrodynamic stability in the annular gap formed by two, vertical, concentric cylinders, the inner being rotated and the outer both stationary and isotermally heated, was studied for the 
Cases of zero and imposed axial fluid flow in the annular gap.

"HEAT TRANSFER BY NATURAL CONVECTION BETWEEN VERTICAL, ENCLOSED, CONCENTRIC CYLINDERS WITH THE INNER CYLINDER HEATED LOCALIY", T. Hanzawa and $K$. Kato, INTERNATIONAL CHEMICAL ENGINEERING, Vol.24, No.4, OCT. 1984

---Heat transfer by natural convection is studied in the annulus between two vertical, concentric cylinder with only part of the inner cylinder heated.

"NATURAL CONVECTION BETWEEN VERTICAL CONCENTRIC CYLINDERS", M. M. Sorour and M. A. Teamah, THERMAI SCIENCES 16: PROCEEDING OF THE 16 SOUTHEASTERN SEMINAR

---This paper describes natural convection flow generated by heat between two vertical concentric cylinders for various radii and aspect ratios. the two cylinders have constant but different temperatures while the two end boundaries are maintained at their mean temperature.

All the above papers deal with heat transfer between the concentric cylinders where the inner cylinder was heated, but their experimental set-up was different than ours. In our case, the inner cylinder will not rotate and the two cylinders do not have constant temperatures, the temperature difference between the cylinders is not small, and there is no opening in the gap.

As part of, this effort a parametric study of the relative distance between two adjacent containers will be made and its effect on the rock temperature. An objective of this study is to try to determine the optimum spacing for these containers so as not to have an overly long drift length to place a certain number of containers which means added cost to the project.

For this study, we wrote a Fortran program using a finitedifference method and Gauss-seidel iteration method to approximate the $2-D$ temperature field $(19.2 \mathrm{~m}$ wide and $300 \mathrm{~m}$ above and below the container, see Figure 2.). The iterative equation of this method is:

$$
T_{i}(k)=\frac{c_{i}}{a_{i i}}-\sum_{j=1}^{i-1} \frac{a_{i j}}{a_{i i}} * T_{j}(k)-\sum_{j=i+1}^{N} \frac{a_{i j}}{a_{i i}} * T_{j}(k-1)
$$


where: $i=1,2, \ldots N$

a and $C$ are the constants come from an energy balance around a temperature node.

The assumptions for this study are: 1 . Two-dimensional conduction in $x-y$ plane. 2. Homogeneous medium with constant properties. 3 . Uniform internal heat generation. 4. Steady state. Also we assumed that the temperature at the top and bottom of the field was $35 \mathrm{C}$, the two edges of the field were adiabatic boundaries, the temperature in the drift was $27 \mathrm{C}$ with wind velocity of 1.016 $\mathrm{m} / \mathrm{sec}$, the thermal conductivity of the rock is $1.8 \mathrm{~W} /(\mathrm{m}, \mathrm{K})$, the heat generation rate was $5000 \mathrm{~W}$. Because of the containers ara assumed $38.4 \mathrm{~m}$ apart the adiabatic lines are the vertical line at the center of the container and the line midway between the two containers, $i . e$. at distance of $19.2 \mathrm{~m}$ away from the container. The temperature profiles of the field are lower than what was found in other studies (see Figure 3. for more detail of the result). The program is attached in Addendum $B$.

It was found that because the relatively low temperature in the near field, the most critical temperature profiles may be found by solving the 2-D transient problem. This way we should be able to capture more details about the temperature changes as time progress and hence address the concerns for the novel container design. Using the steady-state program as a base, we are writing the second program which will solve the transient heat conduction problem. The result of the transient heat transfer analysis can be used to compare with previous near field thermal studies.

\section{FUTURE WORR}

For the future, we will proceed to finish the 2-D transient heat transfer simulation soon, after that a three-dimension computer simulation can be used for better predictions of the rock temperature profiles around the container.

A potential 3-D program called EXACT can handle three dimensional and transient problems along with simulating turbulent flow in the air gap between the borehole wall and the container. The EXACT code is based on primitive variables using finite difference approximations to the governing energy, momentum and continuity equations. This program will give us a way to study the air gap heat transfer problem for this project.

Beside the computer simulations, we propose an experiment set-up 
to study the heat transfer in the vertical, concentric cylinders with the inner cylinder being heated.

In conclusion, for the completed heat transfer study of the project, we need to finish the following:

$<1>$

Analysis of heat transfer inside the waste container.

$<2>$

Analysis of heat transfer in the air gap between the container and the rock borehole wall.

<3>

Computer simulacion of 3-D field temperature profiles of the tuff around the containers. This is for the purpose of determining the optimum spacing for those containers.

$<4>$

Study the effect of heat generated on heat removal from the drifts. 


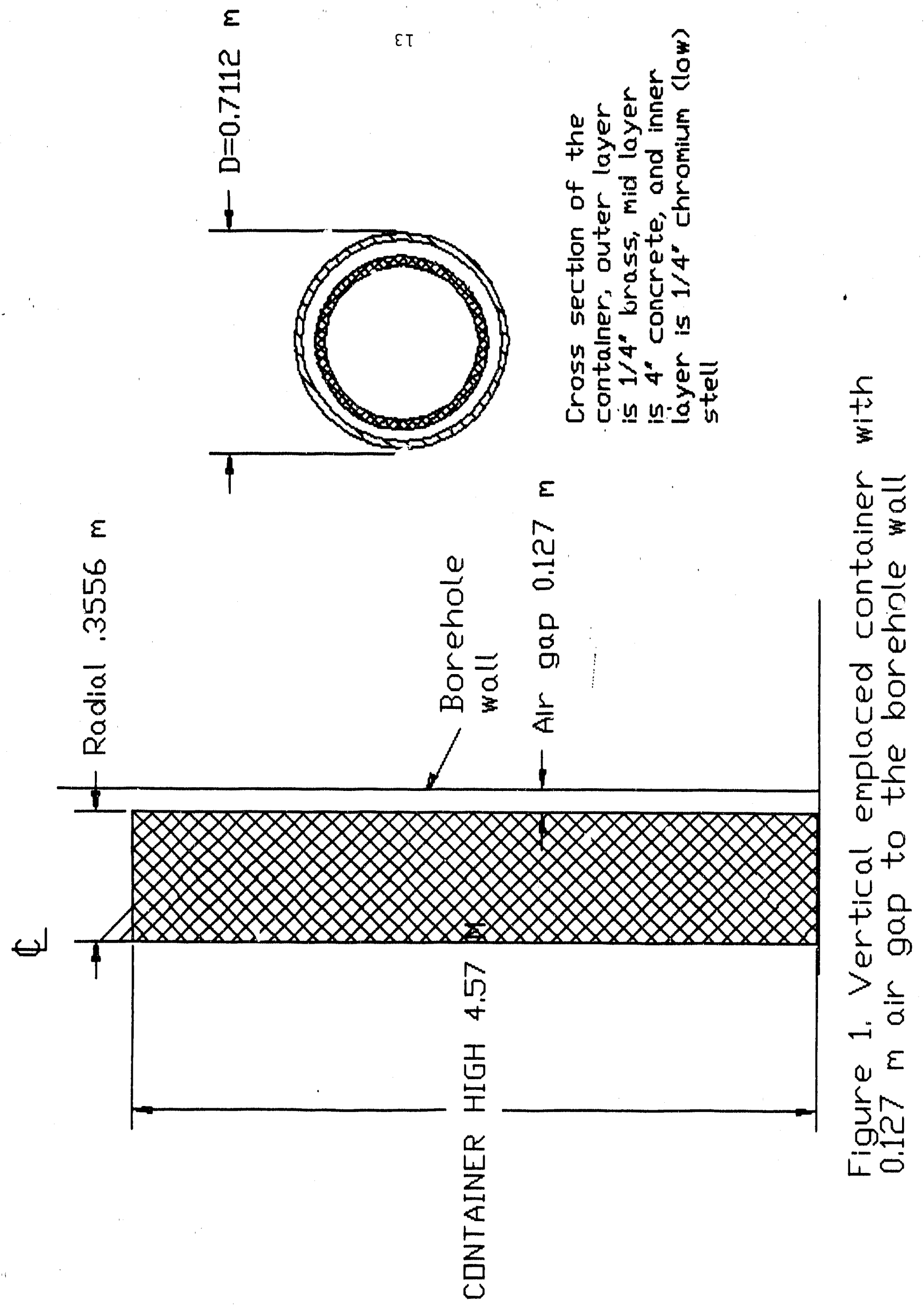




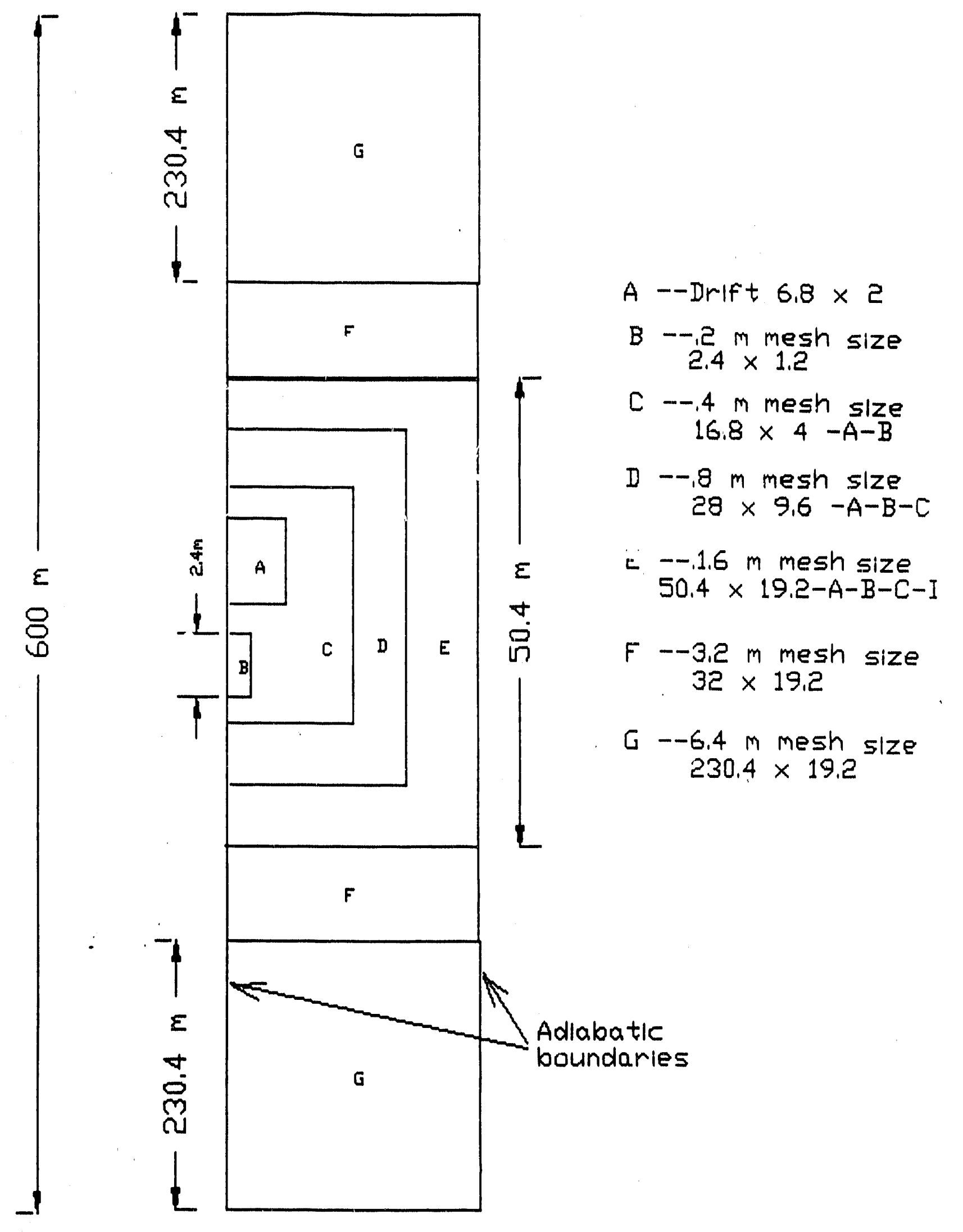

Figure 2. Regions of the six grid sizes in the vertical fleld 


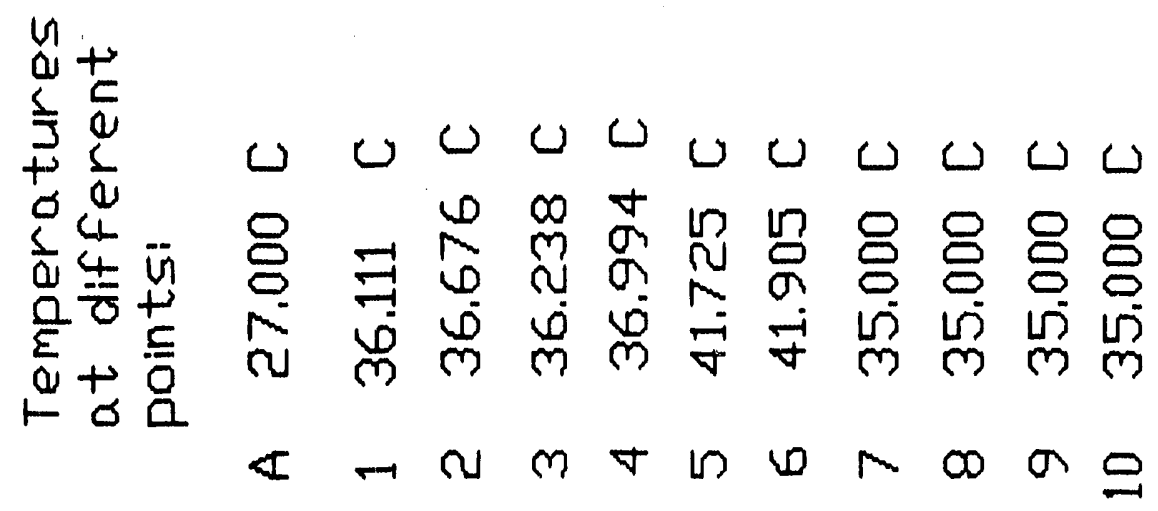

-0
$\frac{1}{4}$
$\frac{1}{0} 5$
$>$

Q $\dot{E}$

$\stackrel{\mathbb{L}}{+} \frac{}{0}$

ᄃ $\frac{\bar{O}}{0}$

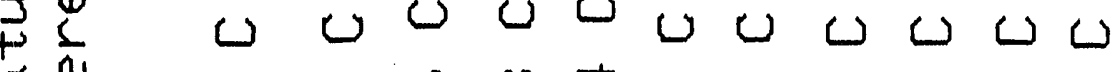

$\underset{+1}{\rightarrow}$ in

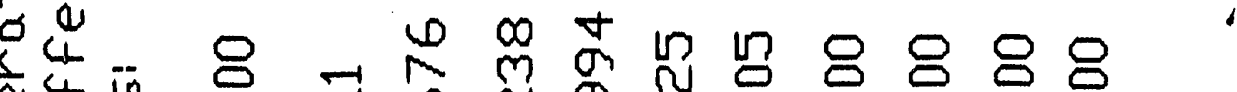

0
$\varepsilon+0$ m

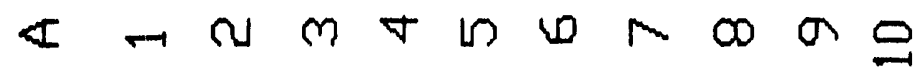

台旦

of 2

प1

a

$\theta \stackrel{4}{0} \stackrel{0}{0}+$

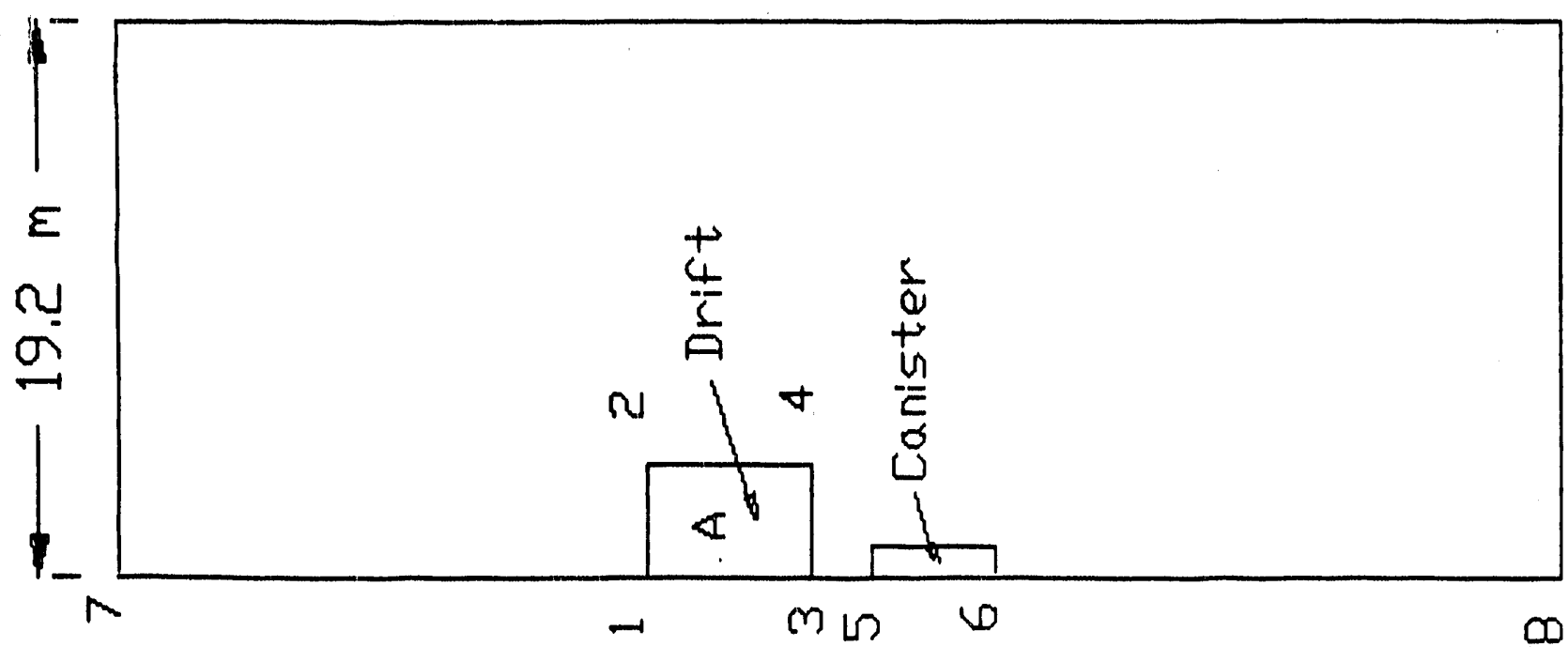

$+8+$

号 ज

$u \leq$

잉

$+\leq 0$

$\frac{0}{0}+$

$\frac{1}{E} \frac{\circlearrowright}{0} \frac{5}{4}$

9

0
$\frac{3}{3}$
$\square$
$\square$

$\varepsilon$ 
ADDENDUM A 


\section{Temperatures on the different wall surfaces when $q=5000 \mathrm{~W}$}

Heat Generating rate:

$$
q 1:=5000 \quad W
$$

Heat Flux:

$$
\text { qr1 }:=489.5 \quad \mathrm{w} / \mathrm{m}^{\wedge} 2
$$

Assuming Temperature at the rock wall:

$\operatorname{Tr}:=368 \quad \mathrm{~K} \quad(95 \mathrm{C})$

THERMOPHYSICAL PROPERTIES OF SOME MATERIALS:

-

heat conductivity:

chromium(low) steel:

kst $:=38.2 \quad w / m \cdot K$

stainless steel AISI 316 :

ksst $:=15.2 \quad \mathrm{w} / \mathrm{m} \cdot \mathrm{K}$

cartridge brass(708 $\mathrm{Cu}, 30 \mathrm{zn})$ :

$\mathrm{kbr}:=137 \quad \mathrm{w} / \mathrm{m} / \mathrm{k}$

concrete(stone mix):

$\operatorname{kcon}:=1.4$

$\mathrm{w} / \mathrm{m} \cdot \mathrm{K}$

Dimensions :

Dimensions:

the high of the tank---

н $:=4.572 \quad \mathrm{~m}$

the thickness of the air gap---

$\mathrm{L}:=.127 \mathrm{~m}$

the radius of the inner steel wall---

$\mathrm{r} 1:=.2413 \quad \mathrm{~m}$

the radius of the outer steel wall---

r2 $:=.24765 \quad \mathrm{~m}$

the radius of the inner brass wall---

r3 $:=.34925$ m

the radius of the outer brass wall---

r4 $:=.3556 \quad \mathrm{~m}$

the radius of the inner rock wall---

r5 $:=.4826$

m

heat convection in the airgap:

$i:=1 \ldots 400$

T $:=368+1 \cdot i$

K 
1

$\mathrm{Ta}_{i}:=\frac{\mathrm{Tr}+\mathrm{T}_{i}}{2}$

$\alpha_{i}:=1.714 \cdot 10^{-7} \cdot \mathrm{Ta}-2.964 \cdot 10^{-5}$

$I_{i}^{\prime}:=1.1454 \cdot 10^{-7} \cdot \mathrm{Ta}_{i}-1.8936 \cdot 10^{-5}$

$\mathrm{k}_{i}:=7.22 \cdot 10^{-5} \cdot \mathrm{Ta}_{i}+.00474$

for $q 1=5000 \mathrm{w}:$

$f 1_{i}:=.42 \cdot\left[9.81 \cdot\left[\frac{1}{\mathrm{Ta}}{ }_{i}\right] \cdot(.127)^{3} \cdot \frac{\mathrm{T}^{-\mathrm{Tr}}}{\alpha_{i} \cdot \Gamma_{i}}\right]^{.25} \cdot\left[\frac{\Gamma}{\alpha_{i}}\right]^{.012} \cdot\left[\begin{array}{l}\mathrm{H} \\ \bar{L}\end{array}\right]^{-.3}$

$h_{i}:=\frac{q r 1}{T_{i}-T r}$

$f 2_{i}:=\operatorname{qr} 1 \cdot(.127) \cdot\left[\frac{1}{k}{ }_{i}\right] \cdot\left[\frac{1}{T_{i}-\mathrm{Tr}}\right]$

$f_{i}:=f 1_{i}-f 2_{i}$

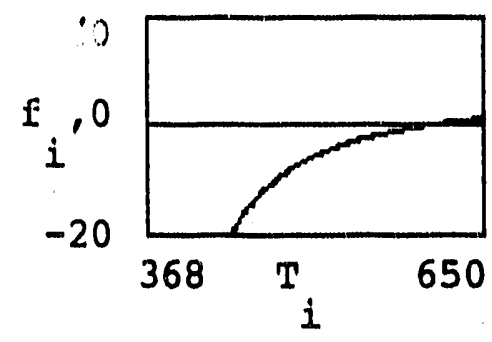

$f_{233}=0.013$

$\mathrm{T}_{233}=601$ 
Radiation exchange between the surface of the tank and the rock wall:

$\epsilon 1:=.8$

$\epsilon 2:=.8$

$\sigma:=5.67 \cdot 10^{-8}$

$W / m^{\wedge} 2 * K^{\wedge} 4$

$\operatorname{Rr}:=\frac{\frac{1}{\epsilon 1}+\frac{1-\epsilon 2}{\epsilon 2} \cdot\left[\frac{r 4}{r 5}\right]}{2 \cdot \pi \cdot r 4 \cdot H}$

Tst $:=\left[\operatorname{Tr}^{4}+q 1 \cdot \frac{R r}{\sigma}\right]^{.25}$

Tst $=418.656 \quad \mathrm{~K}$

heat conductions in the tank walls:

$\mathrm{T} 4:=418.656 \quad \mathrm{~K}$

$$
T 4-273=145.656 \quad C
$$

$T 3:=T 4+\left[q 1 \cdot \frac{\ln \left[\frac{r 4}{r 3}\right]}{2 \cdot \pi \cdot \mathrm{kbr} \cdot \mathrm{H}}\right]$

$\mathrm{T} 3=418.679 \quad \mathrm{~K}$

$\mathrm{T} 3-273=145.679 \quad \mathrm{C}$

$\mathrm{T} 2:=\mathrm{T} 3+\left[q 1 \cdot \frac{\ln \left[\frac{\mathrm{r} 3}{\mathrm{r} 2}\right]}{2 \cdot \pi \cdot \operatorname{kcon} \cdot \mathrm{H}}\right]$

$\mathrm{T} 2=461.418 \quad \mathrm{~K}$

$\mathrm{T} 2-273=188.418$

C

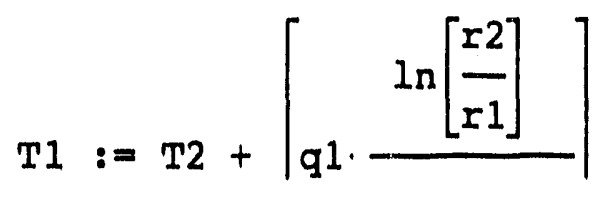


L $2 \cdot \pi \cdot \mathrm{kst} \cdot \mathrm{H}\rfloor$

$$
\mathrm{T} 1=461.536
$$$$
\text { K }
$$

$\mathrm{T} 1-273=188.536$

C 
ADDENDUY B 


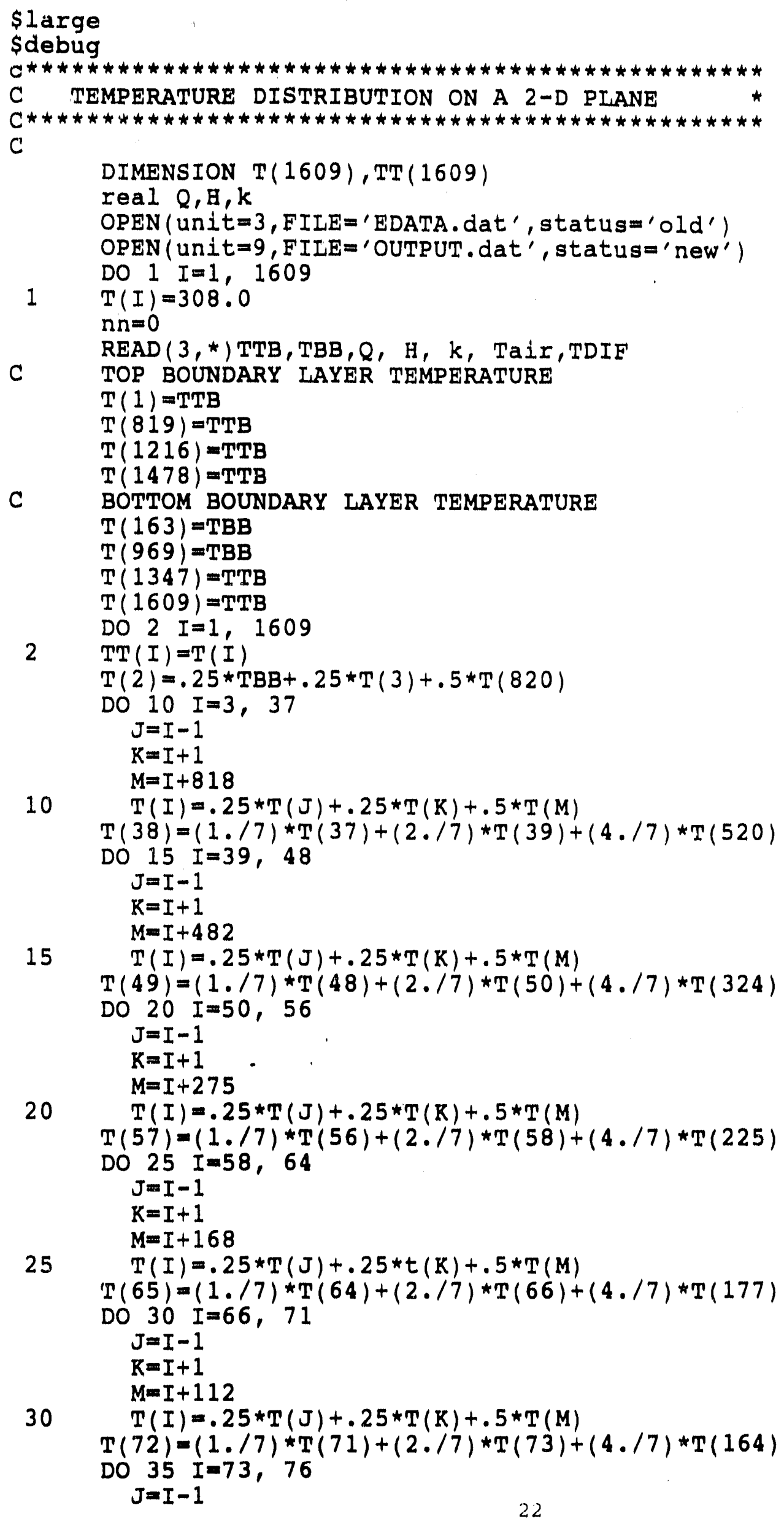




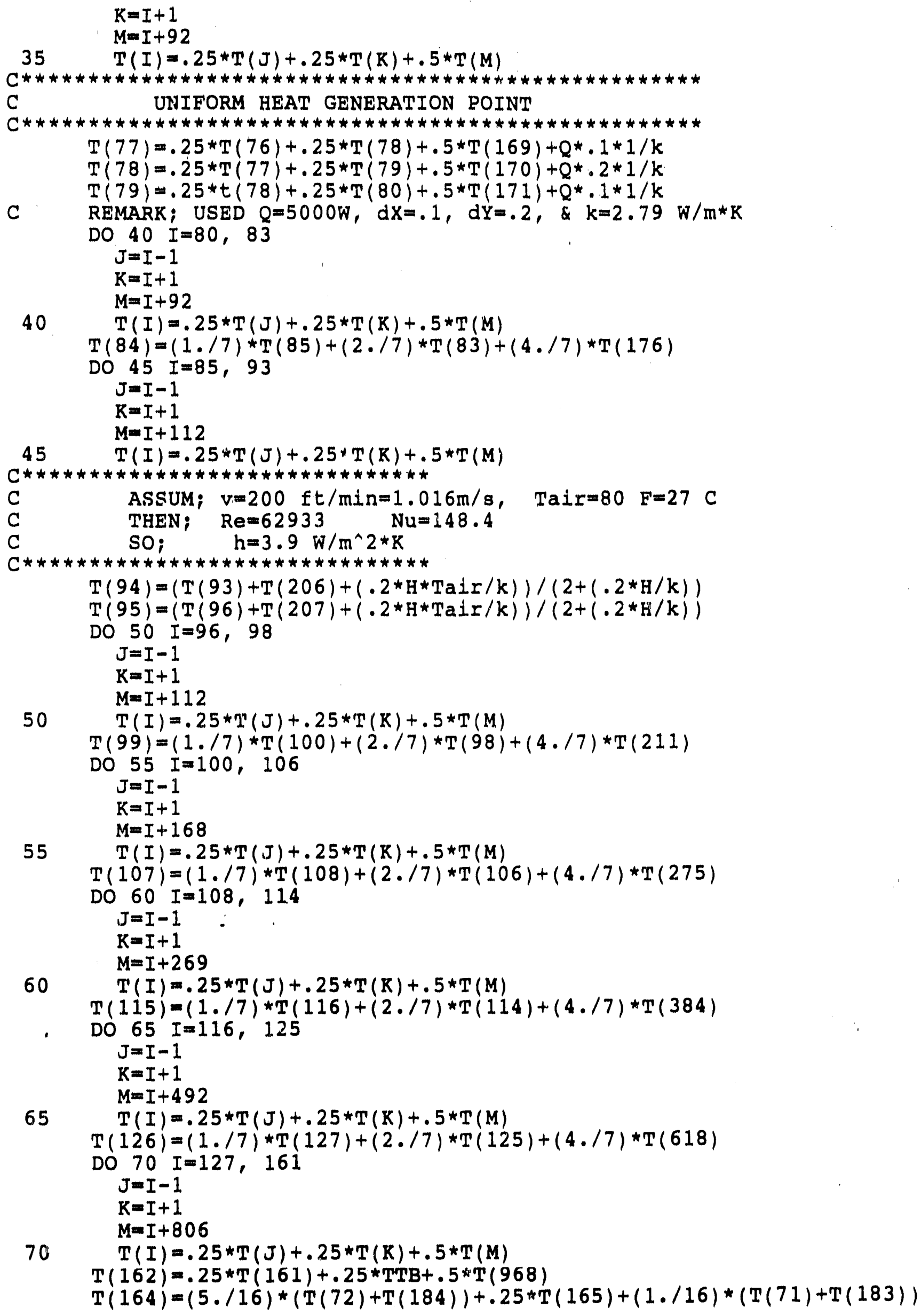




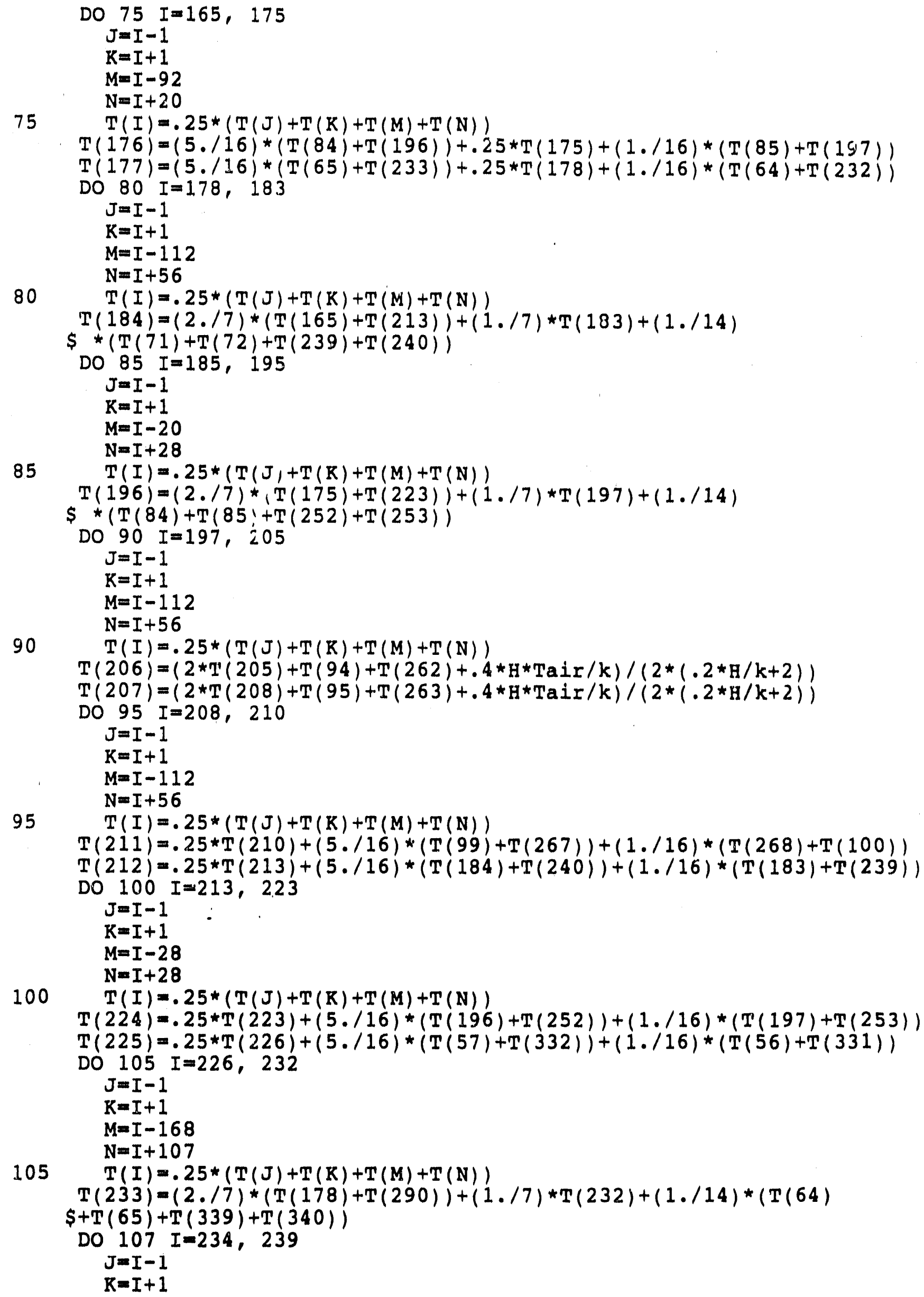




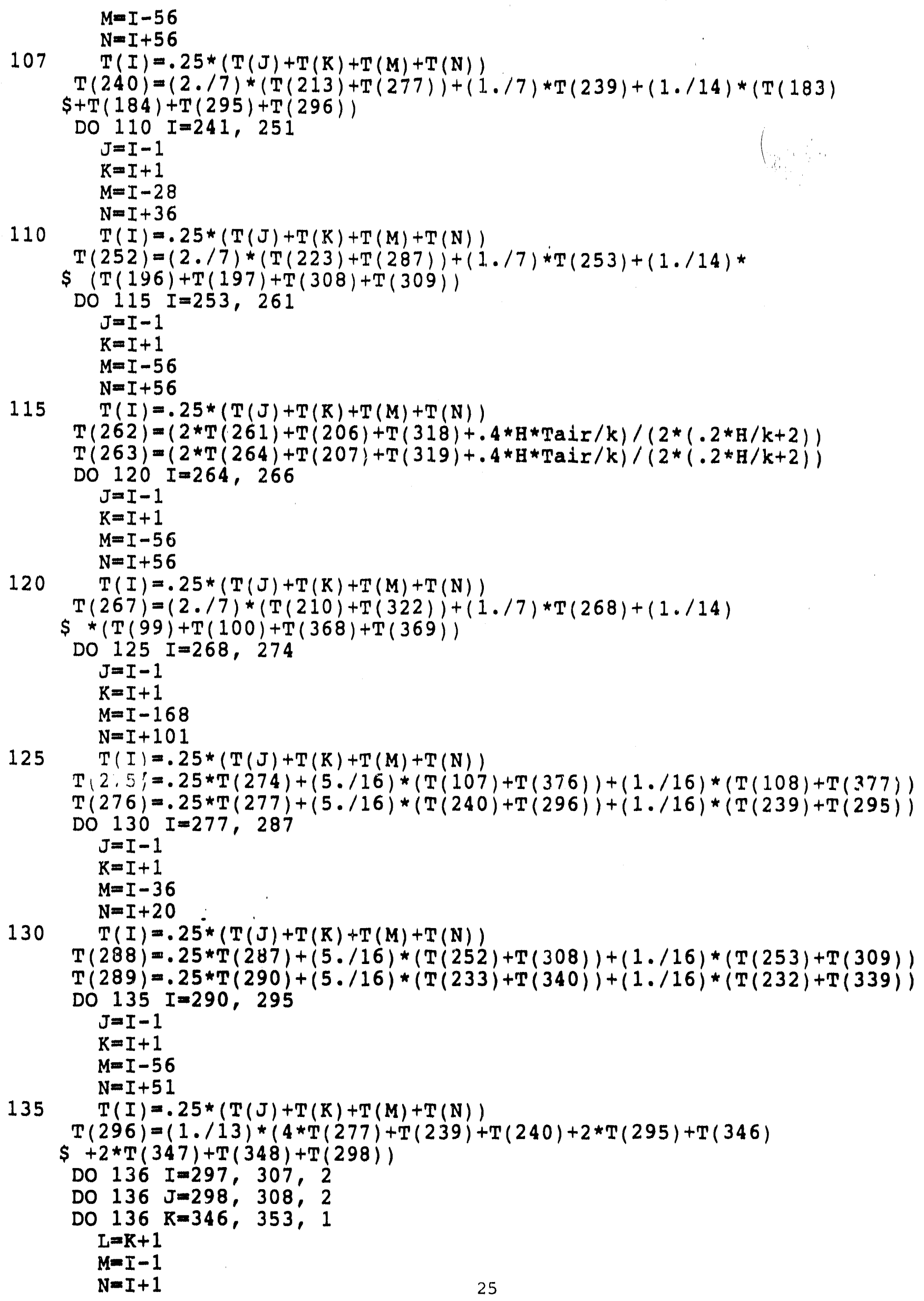




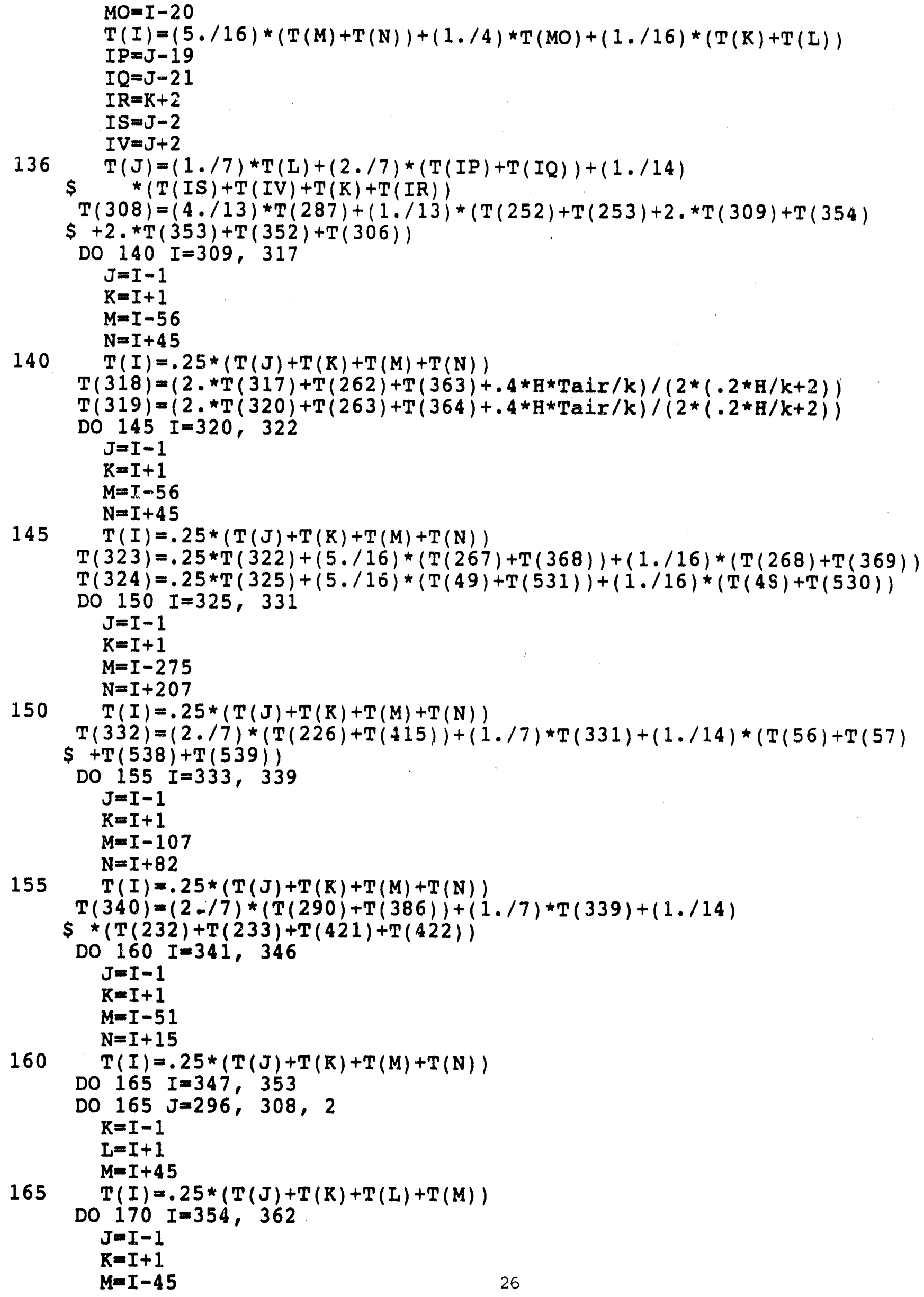




\section{$\mathrm{N}=\mathrm{I}+45$}

$T(I)=.25 *(T(J)+T(K)+T(M)+T(N))$

$T(363)=(2 . * T(362)+T(318)+T(408)+.4 * \mathrm{H} * \mathrm{Tair} / \mathrm{k}) /(2 *(.2 * \mathrm{H} / \mathrm{k}+2))$

$\mathrm{T}(364)=(2 . * \mathrm{~T}(365)+\mathrm{T}(319)+\mathrm{T}(409)+.4 * \mathrm{H} * \mathrm{Tair} / \mathrm{k}) /(2 *(.2 * \mathrm{H} / \mathrm{k}+2))$

DO $175 I=365,367$

$J=I-1$

$\mathrm{K}=\mathrm{I}+1$

$M=I-45$

$\mathrm{N}=\mathrm{I}+45$

$175 T(I)=.25 *(T(J)+T(K)+T(M)+T(N))$

$T(368)=(2 . / 7) *(T(322)+T(412))+(1 . / 7) * T(369)+(1 . / 14) *$

$\$(T(267)+T(268)+T(466)+T(467))$

DO $180 I=369,375$

$$
J=I-1
$$

$\mathrm{R}=\mathrm{I}+1$

$M=I-101$

$N=I+98$

$180 T(I)=.25 *(T(J)+T(R)+T(M)+T(N))$

$T(376)=(2 . / 7) *(T(276)+T(473))+(1 . / 7) * T(377)+(1 . / 14)$

$\$ *(T(107)+T(108)+T(599)+T(600))$

DO $185 I=337,383$

$J=I-1$

$\mathrm{K}=\mathrm{I}+1$

$M=I-269$

$\mathrm{N}=\mathrm{I}+223$

$185 T \mathrm{~T}(\mathrm{I})=.25 *(\mathrm{~T}(\mathrm{~J})+\mathrm{T}(\mathrm{K})+\mathrm{T}(\mathrm{M})+\mathrm{T}(\mathrm{N}))$

$T(384)=.25 * T(383)+(5 . / 16) *(T(115)+T(607))+(1 . / 16) *(T(116)+T(608))$

$\mathrm{T}(385)=.25 * \mathrm{~T}(386)+(5 . / 16) *(\mathrm{~T}(340)+\mathrm{T}(422))+(1 . / 16) *(\mathrm{~T}(339)+\mathrm{T}(421))$

DO $190 I=386,407$

$J=I-1$

$\mathrm{K}=\mathrm{I}+1$

$M=I-45$

$N=I+: 7$

190

$T(I)=.25 *(T(J)+T(R)+T(M)+T(N))$

$T(408)=(2 . * T(407)+T(363)+T(445)+.4 * H * T a i r / k) /(2 *(.2 * H / k+2))$

$\mathrm{T}(409)=(2 . \mathrm{T}(410)+\mathrm{T}(364)+\mathrm{T}(462)+.4 * \mathrm{H} * \mathrm{Tair} / \mathrm{k}) /(2 *(.2 * \mathrm{H} / \mathrm{k}+2))$

DO $195 I=450,412$

$J=I-1$

$\mathrm{K}=\mathrm{I}+1$

$M=I-45$

$\mathrm{N}=\mathrm{I}+53$

$195 T(T)=.25 * i T(J)+T(R)+T(M)+T(N))$

$T(413)=.25 * T(412)+(5 . / 16) *(T(368)+T(466))+(1 . / 16) *(T(369)+T(467))$

$T(414)=.25 * T(415)+(5 . / 16) *(T(332)+T(539))+(1 . / 16) *(T(331)+T(538))$

DO $200 I=415,421$

$J=I-1$

$K=I+1$

$M=I-82$

$\mathrm{N}=\mathrm{I}+125$

200

$T(I)=.25 *(T(J)+T(K)+T(M)+T(N))$

$T(422)=(2 . / 7) *(T(386)+T(476))+(1 . / 7) * T(421)+(1 . / 14)$

$\$ \star(T(339)+T(340)+T(546)+T(547))$

DO $205 I=423,444$

$\mathrm{J}=\mathrm{I}-1$

$K=I+1$

$M=I-37$

$\mathrm{N}=\mathrm{I}+53$

$205 T(I)=.25 *(T(J)+T(R)+T(M)+T(N))$

$T(445)=(2 . *(T(444)+T(498))+T(408)+T(446)+.4 * \mathrm{H} * T a i r / k) /$ 


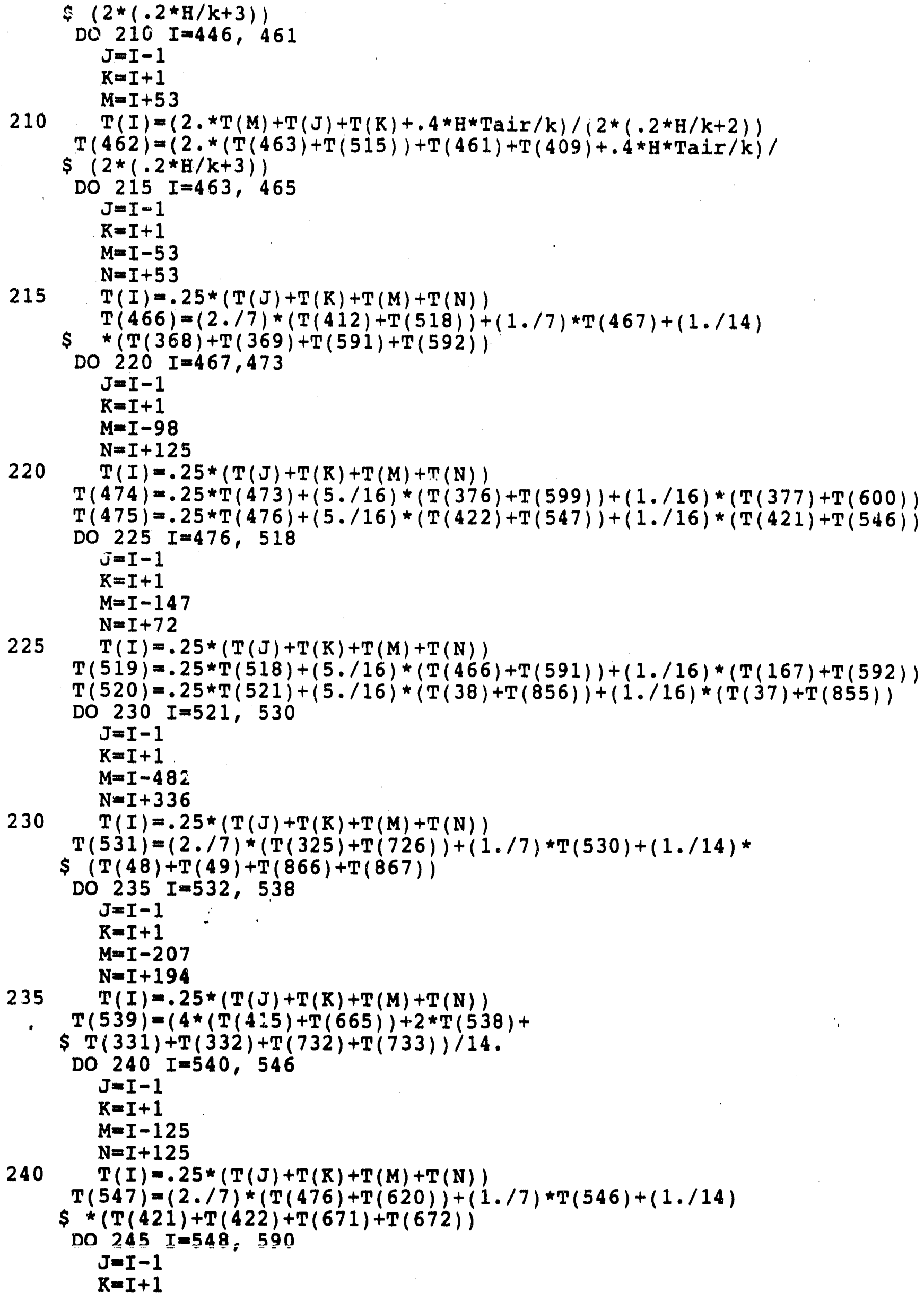




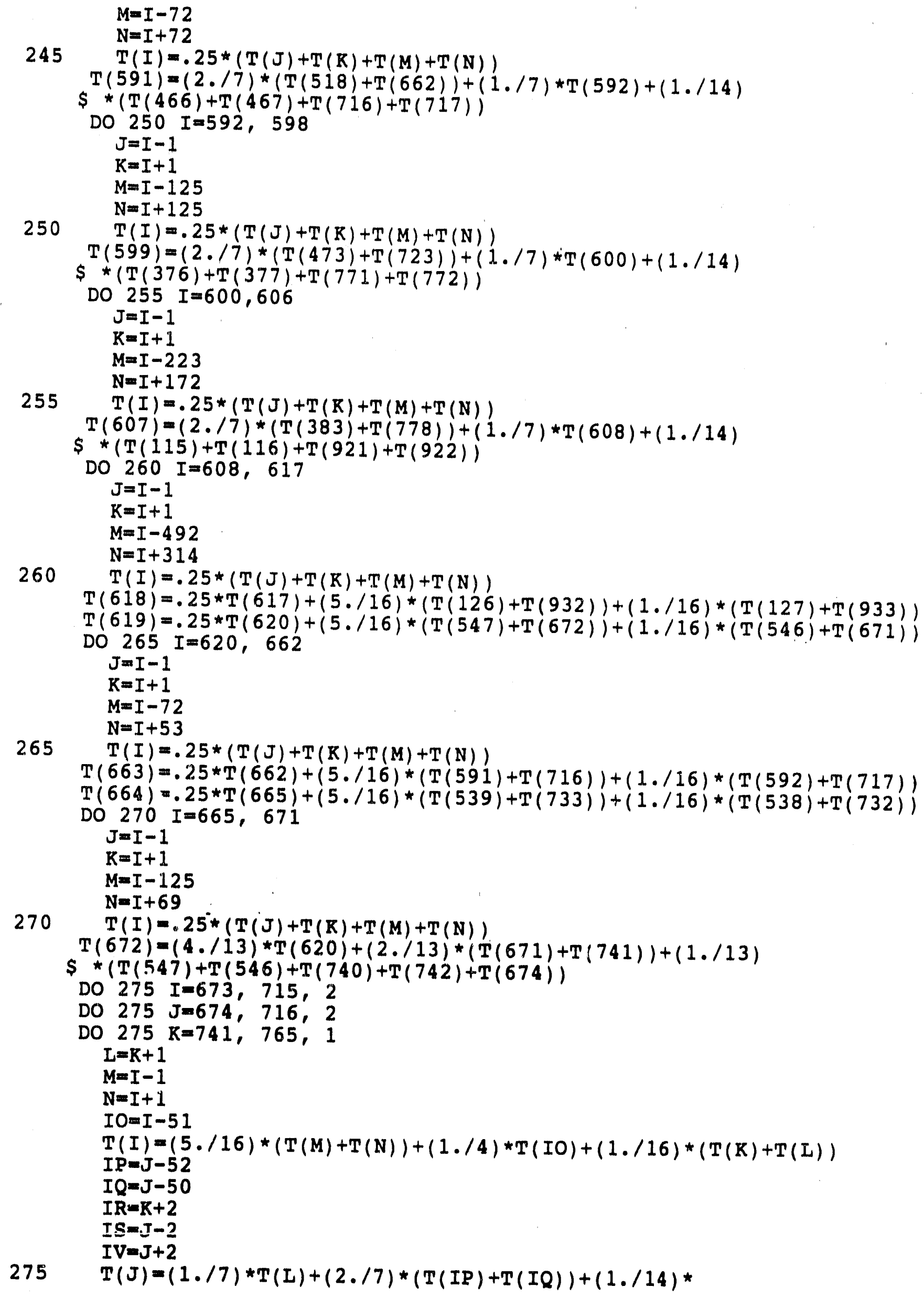




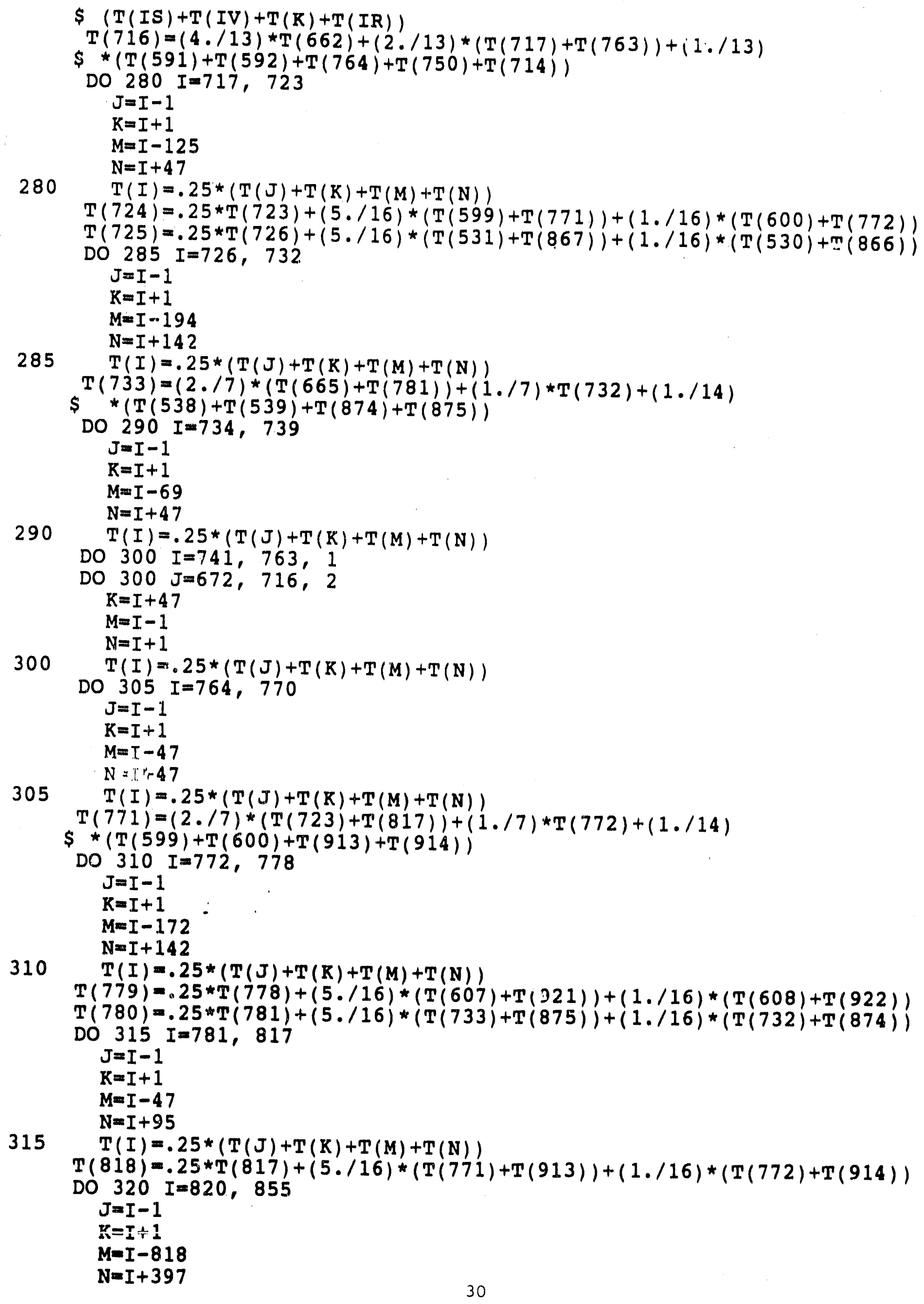


$T(856)=(2 . / 7) *(T(521)+T(1104))+(1 . / 7) * T(855)+(1 . / 14)$

$\$ \star(T(37)+T(38)+T(1252)+T(1253))$

DO $325 I=857,866$

$\mathrm{J}=\mathrm{I}-1$

$\mathrm{K}=\mathrm{I}+1$

$M=I-336$

$\mathrm{N}=\mathrm{I}+247$

$325 T(T)=.25 *(T(J)+T(K)+T(M)+T(N))$

$T(867)=(2 . / 7) *(T(726)+T(1010))+(1 . / 7) * T(866)+(1 . / 14)$

$\$ \star(T(530)+T(531)+T(1113)+T(1114))$

DO $330 I=868,874$

$J=I-1$

$\mathrm{K}=\mathrm{I}+1$

$M=I-142$

$\mathrm{N}=\mathrm{I}+142$

330

$T(I)=.25 *(T(J)+T(K)+T(M)+T(N))$

$T(875)=(2 . / 7) *(T(781)+T(971))+(1 . / 7) * T(874)+(1 . / 14)$

$\$ *(T(732)+T(733)+T(1016)+T(1017))$

DO $335 I=876,912$

$J=I-1$

$\mathrm{K}=\mathrm{I}+1$

$M=I-142$

$\mathrm{N}=\mathrm{I}+95$

$335 T(I)=.25 *(T(J)+T(K)+T(M)+T(N))$

$T(913)=(2 . / 7) *(T(817)+T(1007))+(1 . / 7) * T(914)+(1 . / 14)$

$\$ *(T(771)+T(772)+T(1055)+T(1056))$

DO $340 I=914,920$

$\mathrm{J}=\mathrm{I}-1$

$K=I+1$

$M=I-142$

$\mathrm{N}=\mathrm{I}+142$

340

$T(I)=.25 *(T(J)+T(R)+T(M)+T(N))$

$T(921)=(2 . / 7) *(T(778)+T(1062))+(1 . / 7) * T(922)+(1 . / 14)$

$\$ \star(T(607)+T(608)+T(1168)+T(1169))$

DO $345 I=922,931$

$\mathrm{J}=\mathrm{I}-1$

$\mathrm{K}=\mathrm{I}+1$

$M=I-314$

$\mathrm{N}=\mathrm{I}+247$

$345 T \mathrm{~T}(\mathrm{I})=.25 *(\mathrm{~T}(\mathrm{~J})+\mathrm{T}(\mathrm{K})+\mathrm{T}(\mathrm{M})+\mathrm{T}(\mathrm{N}))$

$T(932)=(2: / 7) *(T(617)+T(1178))+(1 . / 7) * T(933)+(1 . / 14)$

$\$ *(T(126)+T(127)+T(1310)+T(1311))$

DO $350 \quad I=933,968$

$\mathrm{J}=\mathrm{I}-1$

$\mathrm{K}=\mathrm{I}+1$

$M=I-806$

$\mathrm{N}=\mathrm{I}+379$

350

$T(I)=.25 *(T(J)+T(R)+T(M)+T(N))$

$T(970)=.25 * T(971)+(5 . / 16) *(T(875)+T(1017))+(1 . / 16) *(T(874)$

$\$+T(1016))$

DO $355 I=971,1007$

$\mathrm{J}=\mathrm{I}-1$

$\mathrm{K}=\mathrm{I}+1$

$M=I-95$

$\mathrm{N}=\mathrm{I}+47$

$355 \quad T(I j=.25 *(T(J)+T(\bar{K})+T(\bar{T})+T(N) j$

$T(1008)=.25 * \mathrm{~T}(1007)+(5 . / 16) *(\mathrm{~T}(913)+\mathrm{T}(.1055))+(1 . / 16)$

$\$ \star(T(914)+T(1056))$ 
$T(1009)=.25 * T(1010)+(5 . / 16) *(T(867)+T(1114))+(1 . / 16)$

$\$ \star(T(866)+T(1113))$

DO $360 I=1010,1016$

$$
J=I-1
$$

$K=I+1$

$M=I-142$

360

$$
\begin{aligned}
& \mathrm{N}=\mathrm{I}+105 \\
& \mathrm{~T}(\mathrm{I})=.25 *(\mathrm{~T}(\mathrm{~J})+\mathrm{T}(\mathrm{K})+\mathrm{T}(\mathrm{M})+\mathrm{T}(\mathrm{N}))
\end{aligned}
$$

$T(1017)=(2 . / 7) *(T(971)+T(1065))+(1 . / 7) * T(1016)+(1 . / 14)$

$\$ \star(T(874)+T(875)+T(1121)+T(1122))$

DO $365 I=1018,1054$

$J=I-1$

$\mathrm{K}=\mathrm{I}+1$

$M=I-47$

$\mathrm{N}=\mathrm{I}+47$

$365 T(I)=.25 *(T(j)+T(K)+T(M)+T(N))$

$T(1055)=(2 . / 7) *(T(1007)+T(1101))+(1 . i 1) * T(1056)+(1 . / 14) *$

$\$(T(913)+T(914)+T(1160)+T(1161))$

DO $370 I=1056,1062$

$\mathrm{J}=\mathrm{I}-1$

$K=I+1$

$M=I-142$

$\mathrm{N}=\mathrm{I}+105$

$370 T(I)=.25 *(T(J)+T(R)+T(M)+T(N))$

$T(1063)=.25 * T(1062)+(5 . / 16) *(T(921)+T(1168))+(1 . / 16)$

$\$ \star(T(922)+T(1169))$

$T(1064)=.25 * T(1065)+(5 . / 16) *(T(1017)+T(1122))+(1 . / 16)$

$\$ \star(T(1016)+T(1121))$

DO $375 I=1065,1101$

$J=I-1$

$\mathrm{K}=\mathrm{I}+1$

$M=I-47$

$\mathrm{N}=\mathrm{I}+58$

$375 T(I)=.25 *(T(J)+T(R)+T(M)+T(N))$

$T(1102)=.25 * T(1101)+(5 . / 16) *(T(1017)+T(1122))+(1 . / 16)$

$\$ \star(T(1016)+T(1121))$

$T(1103)=.25 * t(1104)+(5 . / 16) *(T(856)+T(1253))+(1 . / 16)$

$\$ \star(T(855)+T(1253))$

DO $380 \quad I=1104,1113$

$J=I-1$

$\mathrm{R}=\mathrm{I}+1$

$M=I-247$ :

$N=I+150$

$380 T(T)=.25 *(T(J)+T(R)+T(M)+T(N))$

$T(1114)-(2 . / 7) *(T(1010)+T(1181))+(1 . / 7) * T(1113)+(1 . / 14)$

$\$ *(T(866)+T(867)+T(1263)+T(1264))$

DO $385 \mathrm{I}=1115,1121$

$\mathrm{J}=\mathrm{I}-1$

$R=I+1$

$M=I-105$

$N=I+66$

$385 T(T)=.25 *(T(J)+T(R)+T(M)+T(N))$

$T(1122)=(4 . / 13) * T(1065)+(2 . / 13) *(T(1121)+T(1188))+(1 . / 13)$

$\$ \star(T(1016)+T(1017)+T(1187)+T(1189)+T(1124))$

DO $390 I=1123,1159,2$

DO $390 \mathrm{~J}=1124$, 1160, 2

DO $390 \mathrm{~K}=1188,1207,1$

$\mathrm{L}=\mathrm{K}+1$

$M=I-1$ 


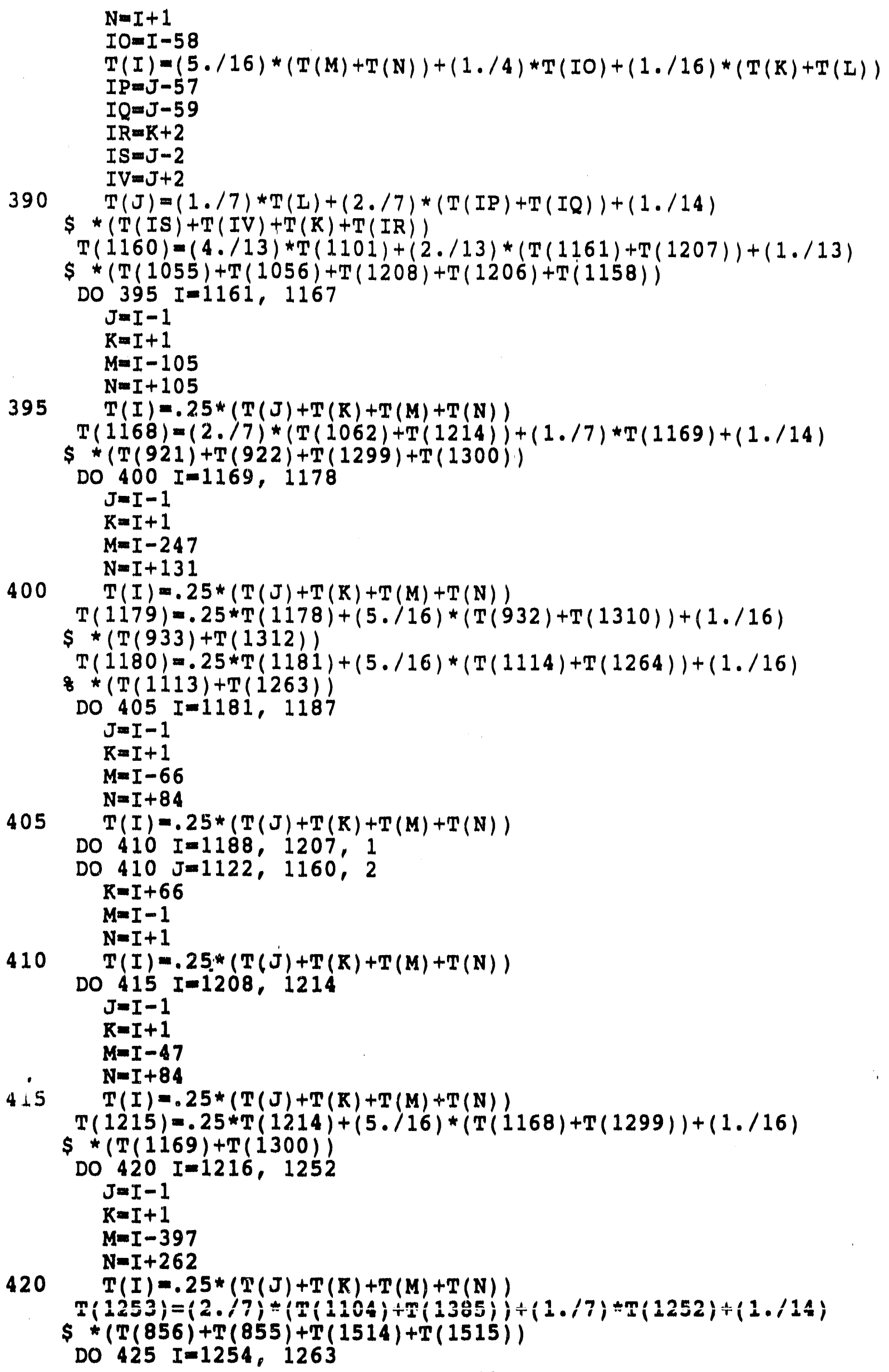




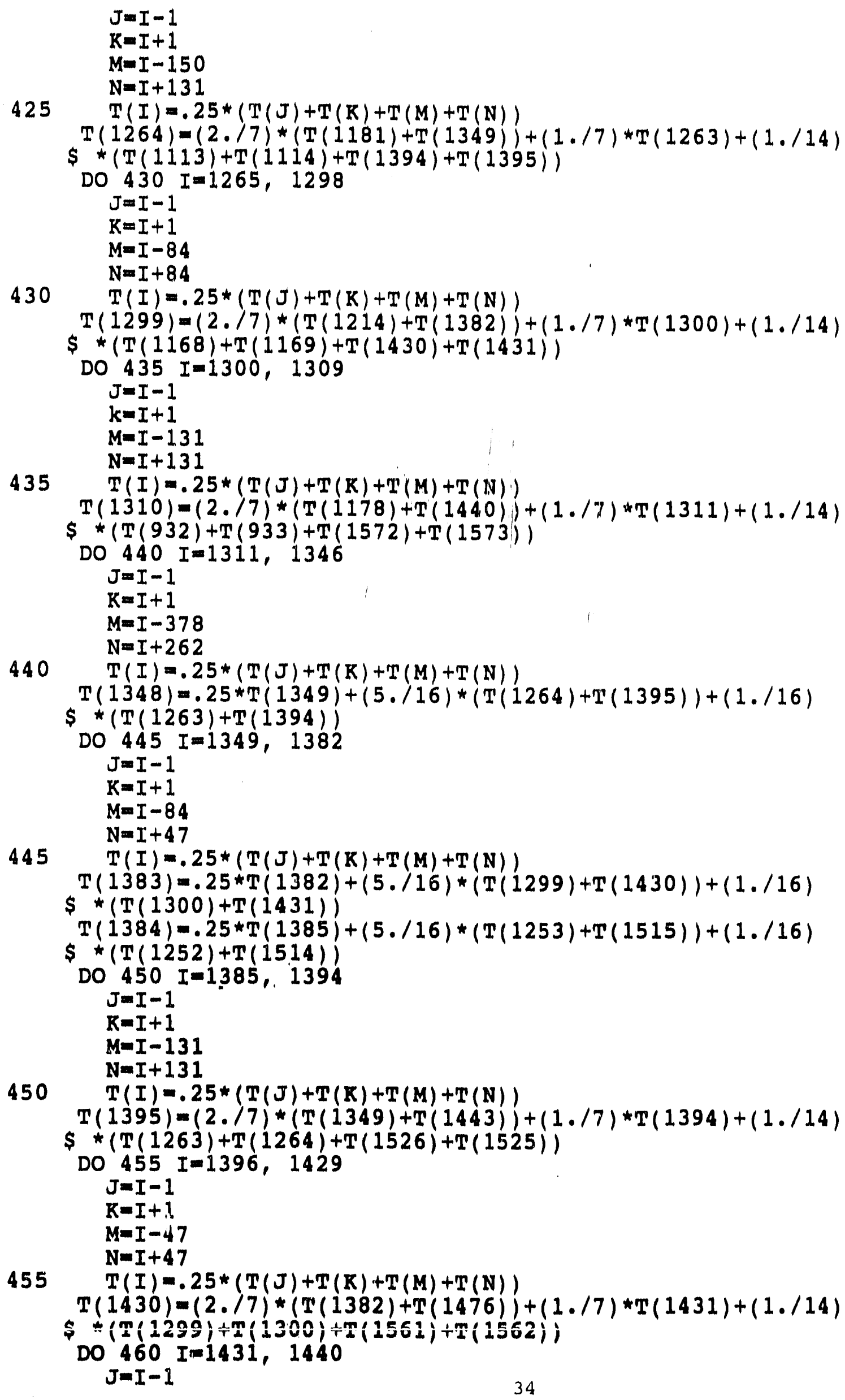




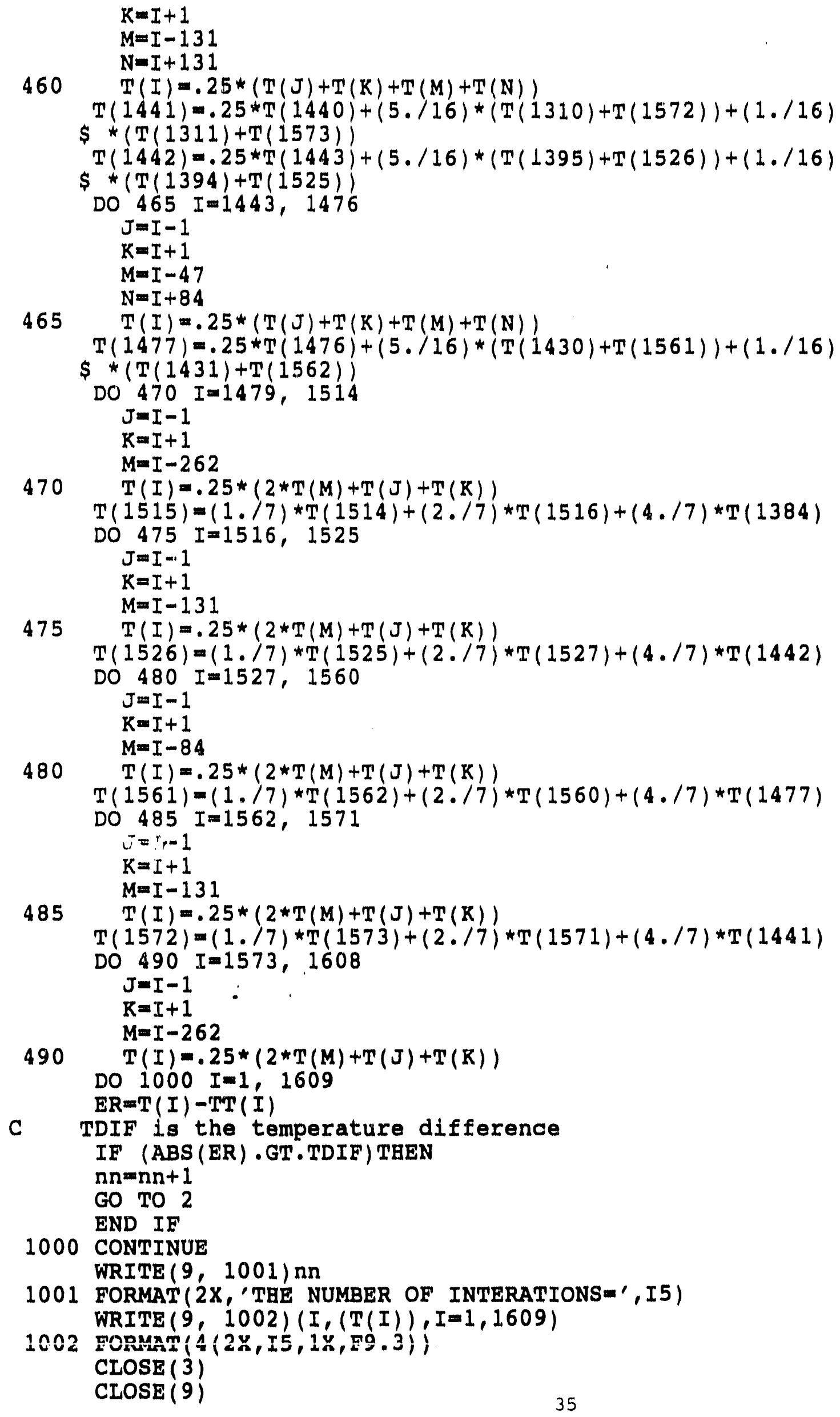


STOP

END 

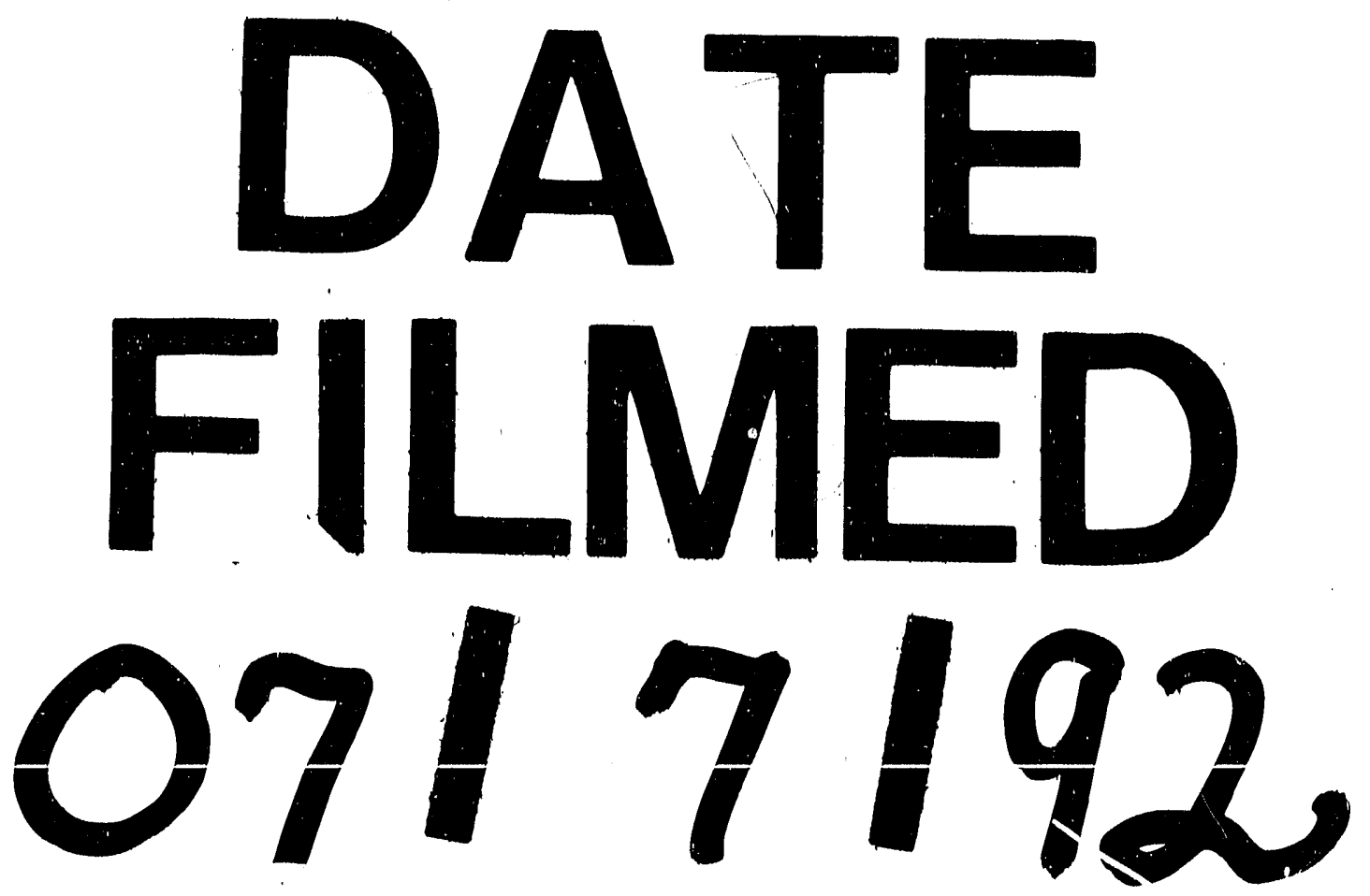

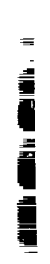


